\title{
EVALUACION INICIAL EN POBLACIONES HETEROGENEAS DE CAMOTE (lpomea Batatas (L.) lam) EN TACNA.
}

Nelly Arevalo Sol Sol

\section{RESUMEN}

Se realizó un estudio para determinar la variabilidad de una población de 510 clones de camote procedentes de EE.UU., Japón, Ruanda, China y Perú, así como seleccionar clones por uniformidad de rendimiento y porcentaje de materia seca. La variabilidad morfológica en la población fue estudiada en 12 caracteres. Detectándose una amplia variabilidad entre los diferentes caracteres evaluados: peso total, peso comercial, color de piel, color de pulpa, cuarteaduras, pubescencia de tallos, tipo de lóbulo, número de lóbulos, forma de-lóbulos, pigmentación de venas y tallos. Se han seleccionado 62 clones en base a su rendimiento, materia seca y aspectos cuantitativos, destacando el clon $C H G U$ 3.12 por su buen rendimiento y porcentaje de materia seca.

\section{INTRODUCCION}

El germoplasma de camote es una fuente importante para un programa de mejoramiento. Los recursos genéticos deben ser evaluados para emplearlos eficientemente en la creación de material promisorio. Se necesita tener mayor información acerca de las características morfológicas de la planta, su asociación con el rendimiento y la influencia del ambiente. El rendimiento es afectado significativamente por las interacciones genotipo por ambiente.

En el proceso de selección se debe considerar factores que pudieran modificar su efectividad, tal como correlaciones con otros caracteres importantes y la interacción con el ambiente. La eficiencia de la selección también dependerá del grado de variabilidad genética presente en la población

La selección inicial es un paso previo en el mejoramiento genético del camote, para la selección de clones con objeto de incrementar el potencial y la estabilidad de rendimiento, así como incorporar atributos específicos de precocidad, calidad y resistencia a factores adversos bióticos (insectos, hongos, nemátodos) y abióticos (salinidad, sequía, boro), Se plantea el presente trabajo de investigación con la finalidad de realizar selección clonal de acuerdo a nuestros requerimientos y las condiciones de suelo árido salinas de Tacna (clones precoces de buenos atributos agronómicos y tolerantes a la salinidad) en una población heterogénea de camote.

Los objetivos del presente estudio son : estudiar la variabilidad de una población heterogénea, seleccionar clones promisorios por rendimiento, materia seca y atributos deseables.

\section{MATERIALES Y METODOS}

\section{UBICACION DEL EXPERIMENTO}

El presente experimiento se llevó a cabo en el Campo Experimental Agrícola La Yarada (CEA II) de la Universidad Nacional «Jorge Basadre Grohmann de tacna.

\section{CARACTERISTICAS CLIMATICAS}

El experimento se condujo de abril 1993 hasta junio de 1994. La temperatura media máxima se registró en los meses de enero y febrero $\left(21.20^{\circ} \mathrm{C}\right.$ y 22.42 ${ }^{\circ} \mathrm{C}$ respectivamente) y la temperatura media mínima se registrarón en los meses de julio y agosto $\left(13.2^{\circ} \mathrm{C}\right.$ y $14.0^{\circ} \mathrm{C}$ respectivamente).] 
Se utilizó esquejes de camote obtenidos a partir de semilla sexual, de cinco poblaciones heterogéneas logradas de policruzas (OP) y cruzamientos dirigidos: EE.UU., China, Japón, Ruanda y Perú, utilizando 510 clones y 102 progenies por población.

\section{METODOS Y PROCEDIMIENTOS}

Las semillas fueron tratadas con ácido sulfúrico $98 \%$ por un tiempo aproximado de 40 minutos, posteriormente se lavó varias veces con abundante agua y luego se dejó en agua por 24 horas, con la finalidad de retirar los residuos del ácido, así como uniformizar la germinación.

Inmediatamente después de la escarificación y el lavado, las semillas fueron colocadas en placas petri con papel filtro humedecido para su germinación (5 a 8 dias). Las semillas germinadas fueron puestas en Jiffy-7 (comprimido de musgo) para el crecimiento de plántulas durante 2 meses: estos Jiffys con las plántulas se colocaron en macetas con arena, los cuales estuvieron cubiertos con mallas para protegerlos de los insectos vectores de virus; las plántulas recibirán riegos constantes, aplicaciones de abonos foliares e insecticidas; además se despuntaron las dos hojas laterales, con el objeto de estimular la formación de yemas laterales; seguidamente fueron llevadas al campo para su aclimatación y multiplicación de esquejes (3 meses), posteriormente estos esquejes fueron utilizadas en la instalación del experimento.

\section{DISEÑO ESTADISTICO}

El diseño estadístico empleado fue el de Bloques Completos Randomizados (BCR) usando 510 clones en tres repeticiones.

\section{CARACTERES DE EVALUACION}

Caracteres cuantitativos: Rendimiento de raíces comerciales por planta, número total y comercial de raíces reservantes, materia seca.

Caracteres cualitativos: Color de piel, color de pulpa, craking, tipo de lóbulo en hoja, forma de lóbulo de la hoja, color de hojas, pubescencia , número de lóbulos, perfil de hojas fueron evaluados según la escala propue: ta por el IBPGR, modificado por Huamán (1988).

\section{CRITERIOS DE SELECCION}

Alto rendimiento comercial, uniformidad aceptable de raíces reservantes tanto en forma como en tamaño., ausencia de autocianina en la pulpa, sin deformaciones, ausencia de antocianina en la pulpa, si deformaciones, ausencia de brotamiento en las raíces reservantes al momento de la cosecha, tolerancia a en- fermedades y plagas y buen contenido de materia seca.

\section{RESULTADOS Y DISCUSIÓN}

\section{VARIABILIDAD DE LA POBLACIÓN HETEROGÉNEA DE CAMOTE}

Los clones de camote son poblaciones homogéneas probablemente con diverso grado de heterocigocidad, debido al carácter poliploide $2 n=6 x=90$ cromosomas: BBBBBB, y cuya expresión derminará el grado de adaptación tal como lo señala Arévalo (1992). Por lo tanto, es importante considerar el empleo de variedades adaptadas como la mejor alternativa para disminuir la interacción genotipo $x$ ambiente, como también fue sugerido por Collins (1987) y Arévalo (1992)

- CUADRO 1. VARIABILIDAD DE UNA POBLACION DE 510 CLONES DE CAMOTE EVALUADOS EN TACNA. 1993.

\begin{tabular}{|l|l|r|r|r|}
\hline Características & \multicolumn{1}{|c|}{ Rango } & Media & \multicolumn{1}{c|}{ sd } & CV (\%) \\
\hline 1. Peso total en g & $105.0-3550.0$ & 1062.8 & 500.2 & 47.1 \\
2. Peso comercial g & 50.04050 .0 & 927.6 & 468.8 & 50.5 \\
3. Color de piel & $1-4$ & 5.20 & 2.30 & 43.1 \\
4. Color de pulpa & $1-9$ & 4.70 & 2.50 & 53.3 \\
5. Craking & $1-1$ & 1.00 & 0.3 & 31.2 \\
6. Pubescencia & $0-7$ & 2.50 & 1.90 & 75.1 \\
7. Perfil de hoja & $3-7$ & 4.40 & 1.3 & 28.8 \\
8. Tipo de lóbulo & $1-9$ & 2.50 & 2.20 & 87.8 \\
9. No de lóbulos & $1-5$ & 2.30 & 1.80 & 79.0 \\
10. Forma de lóbulos & $1-9$ & 2.40 & 2.10 & 85.5 \\
11. Pigmento de venas & $1-7$ & 3.30 & 1.50 & 43.9 \\
\hline
\end{tabular}


CUADRO 2. ClONES SELECCIONADOS DE CAMOTE EN POBLACION HETERO -GENEA. TACNA. 1993 (1) MATERIAL CHINO

\begin{tabular}{llllllllllllllll}
\hline Clones & 1 & 2 & 3 & 4 & 5 & 6 & 7 & 8 & 9 & 10 & 11 & 12 & 13 & 14 & 15 \\
\hline CHGU 7.4 & 0.80 & 0.73 & 7.0 & 3.0 & 4 & 6 & 1 & 2 & 4 & 3 & 3 & 3 & 3 & 4 & 19.77 \\
CHGU 4.3 & 0.78 & 0.72 & 3.7 & 1.7 & 2 & 6 & 1 & 2 & 5 & 3 & 3 & 3 & 4 & 3 & 20.35 \\
CHGU 3.12 & 3.43 & 3.40 & 4.0 & 4.5 & 1 & 3 & 1 & 2 & 5 & 3 & 3 & 4 & 4 & 5 & 30.25 \\
CHGU 1.5 & 2.43 & 1.90 & 7.5 & 4.0 & 6 & 3 & 1 & 4 & 5 & 3 & 3 & 3 & 3 & 3 & 26.78 \\
CHGU 9.13 & 1.78 & 1.68 & 5.5 & 4.0 & 6 & 3 & 1 & 2 & 5 & 3 & 3 & 3 & 3 & 4 & 26.35 \\
CHGU 3.14 & 2.37 & 1.05 & 5.3 & 3.0 & 7 & 7 & 1 & 2 & 4 & 3 & 3 & 3 & 4 & 3 & 21.77 \\
CHGU 4.12 & 1.42 & 1.38 & 6.3 & 5.0 & 2 & 3 & 1 & 2 & 5 & 3 & 3 & 3 & 4 & 3 & 24.88 \\
CHGU 9.11 & 0.60 & 0.60 & 3.0 & 3.0 & 4 & 7 & 1 & 2 & 5 & 4 & 3 & 3 & 4 & 4 & 35.76 \\
\hline
\end{tabular}

MATERIAL NORTEAMERICANO

\begin{tabular}{|c|c|c|c|c|c|c|c|c|c|c|c|c|c|c|c|c|}
\hline Clones & & 1 & 2 & 3 & 4 & 5 & 6 & 7 & 8 & 9 & 10 & 11 & 12 & 13 & 14 & 15 \\
\hline USSC & 5.15 & 0.95 & 0.83 & 2.7 & 1.3 & 5 & 7 & 1 & 3 & 4 & 1 & 2 & 2 & 3 & 3 & 21.59 \\
\hline USSC & 5.11 & 2.00 & 1.58 & 6.0 & 3.5 & 4 & 7 & 1 & 3 & 5 & 2 & 2 & 3 & 2 & 4 & 19.28 \\
\hline USSC & 5.9 & 0.80 & 0.67 & 5.3 & 3.7 & 5 & 7 & 1 & 3 & 4 & 2 & 3 & 2 & 3 & 5 & 20.34 \\
\hline USSC & 3.14 & 0.90 & 0.92 & 4.0 & 2.7 & 4 & 8 & 1 & 3 & 4 & 1 & 1 & 1 & 3 & 3 & 22.59 \\
\hline USSC & 3.13 & 1.70 & 1.50 & 6.5 & 5.0 & 5 & 8 & 1 & 2 & 5 & 2 & 3 & 2 & 2 & 5 & 21.30 \\
\hline USSC & 2.4 & 1.43 & 4.28 & 3.0 & 2.7 & 8 & 8 & 1 & 3 & 4 & 1 & 2 & 1 & 3 & 4 & 25.40 \\
\hline USSC & 10.17 & 1.47 & 1.33 & 5.3 & 4.7 & 8 & 8 & 1 & 3 & 5 & 2 & 2 & 3 & 3 & 3 & 21.16 \\
\hline USSC & 3.8 & 0.97 & 0.92 & 5.0 & 4.3 & 6 & 6 & 1 & 2 & 4 & 1 & 3 & 2 & 3 & 5 & 21.16 \\
\hline USSC & 3.3 & 1.70 & 1.70 & 2.67 & 2.67 & 5 & 5 & 1 & 3 & 5 & 2 & 2 & 3 & 3 & 5 & 28.02 \\
\hline USCC & 3.4 & 2.65 & 1.35 & 9.0 & 3.0 & 7 & 1 & 1 & 3 & 4 & 1 & 2 & 1 & 3 & 4 & 20.62 \\
\hline USCC & 23.2 & 1.65 & 1.43 & 9.5 & 6.5 & 6 & 1 & 2 & 4 & 2 & 2 & 2 & 2 & 3 & 4 & 21.82 \\
\hline USSC & 23.1 & 0.73 & 0.73 & 3.0 & 3.0 & 7 & 8 & 1 & 3 & 5 & 2 & 3 & 3 & 3 & 5 & 20.90 \\
\hline USSC & 11.3 & 1.05 & 1.02 & 6.5 & 5.0 & 7 & 8 & 1 & 3 & 4 & 2 & 3 & 3 & 2 & 5 & 20.34 \\
\hline USSC & 11.10 & 1.60 & 1.43 & 14.0 & 8.0 & 6 & 7 & 1 & 3 & 4 & 2 & 2 & 2 & 3 & 3 & 24.18 \\
\hline USSC & 11.12 & 1.22 & 1.10 & 10.0 & 7.0 & 4 & 7 & 1 & 3 & 4 & 1 & 1 & 2 & 2 & 3 & 26.57 \\
\hline USSC & 11.19 & 1.13 & 1.10 & 7 & 6.3 & 4 & 8 & 1 & 2 & 4 & 2 & 1 & 2 & 3 & 3 & 24.45 \\
\hline USSC & 11.9 & 1.83 & 1.73 & 11.0 & 8.0 & 4 & 7 & 1 & 3 & 5 & 2 & 2 & 3 & 2 & 3 & 20.20 \\
\hline USSC & 11.16 & 1.58 & 1.58 & 6 & 6 & 6 & 7 & 1 & 3 & 5 & 2 & 2 & 3 & 3 & 5 & 25.31 \\
\hline USSC & 11.17 & 1.52 & 1.20 & 11 & 8.35 & 7 & 8 & 1 & 3 & 4 & 1 & 2 & 2 & 2 & 3 & 20.44 \\
\hline USSC & 11.18 & 1.63 & 1.50 & 9.3 & 7.0 & 5 & 7 & 1 & 3 & 4 & 2 & 1 & 3 & 3 & 3 & 23.65 \\
\hline USSC & 6.20 & 0.85 & 0.85 & 4.0 & 4.0 & 5 & 6 & 1 & 2 & 5 & 1 & 2 & 2 & 2 & 5 & 34.42 \\
\hline USSC & 6.10 & 1.20 & 0.85 & 7 & 4 & 4 & 7 & 1 & 3 & 4 & 1 & 2 & 2 & 3 & 3 & 26.45 \\
\hline USSC & 11.14 & 1.40 & 1.4 & 3 & 3.0 & 4 & 8 & 1 & 2 & 4 & 2 & 2 & 2 & 2 & 5 & 20.20 \\
\hline USSC & 11.15 & 1.55 & 1.45 & 9.7 & 8.0 & 7 & 8 & 1 & 3 & 4 & 1 & 1 & 3 & 3 & 3 & 19.61 \\
\hline USSC & 3.7 & 1.67 & 1.67 & 7 & 7 & 5 & 6 & 1 & 2 & 5 & 1 & 2 & 1 & 2 & 3 & 23.58 \\
\hline USSC & 3.5 & 0.70 & 0.62 & 4.7 & 3 & 4 & 8 & 1 & 3 & 4 & 2 & 1 & 1 & 3 & 3 & 22.98 \\
\hline USSC & 8.10 & 2.18 & 1.07 & 11.5 & 9.0 & 5 & 7 & 1 & 3 & 4 & 1 & 1. & 2 & 2 & 3 & 24.42 \\
\hline USSC & 10.20 & 1.33 & 1.13 & 9.5 & 6.5 & 3 & 8 & 1 & 2 & 4 & 1 & 2 & 2 & 3 & 3 & 26.41 \\
\hline
\end{tabular}




\section{MATERIAL JAPONES}

\begin{tabular}{llllllllllllllll}
\hline Clones & 1 & 2 & 3 & 4 & 5 & 6 & 7 & 8 & 9 & 10 & 11 & 12 & 13 & 14 & 15 \\
\hline JPKY 16.6 & 1.10 & 1.10 & 3.0 & 3.0 & 2 & 2 & 1 & 3 & 5 & 1 & 2 & 1 & 3 & 3 & 31.19 \\
JPKY 10.14 & 1.38 & 1.38 & 5.0 & 5.0 & 7 & 2 & 1 & 4 & 4 & 2 & 1 & 2 & 4 & 4 & 41.64 \\
JPKY 19.17 & 0.98 & 0.73 & 10 & 6 & 9 & 3 & 1 & 5 & 5 & 4 & 3 & 4 & 3 & 3 & 29.28 \\
JPKY 19.6 & 0.81 & 0.63 & 4.3 & 2.3 & 5 & 5 & 1 & 5 & 5 & 1 & 4 & 1 & 4 & 4 & 32.78 \\
JPKY 20.10 & 1.78 & 1.60 & 6.5 & 4.5 & 4 & 4 & 1 & 3 & 5 & 4 & 2 & 2 & 3 & 3 & 31.87 \\
JPKY 20.14 & 1.43 & 1.25 & 5.0 & 4.0 & 2 & 5 & 1 & 4 & 4 & 2 & 1 & 4 & 4 & 4 & 31.30 \\
JPKY 4.20 & 1.67 & 1.67 & 2.7 & 2.7 & 8 & 4 & 1 & 5 & 5 & 4 & 4 & 4 & 4 & 3 & 31.19 \\
JPKY 4.7 & 2.00 & 1.95 & 4.5 & 4.0 & 6 & 3 & 1 & 5 & 5 & 1 & 3 & 1 & 4 & 4 & 40.64 \\
JPKY 16.12 & 1.10 & 1.05 & 6.3 & 5.3 & 7 & 3 & 1 & 3 & 4 & 2 & 4 & 1 & 3 & 4 & 35.53 \\
JPKY 16.20 & 1.17 & 1.13 & 5.7 & 5 & 7 & 4 & 1 & 4 & 5 & 4 & 2 & 4 & 3 & 3 & 34.44 \\
JPKY 15.10 & 1.55 & 1.38 & 7.5 & 4.5 & 6 & 4 & 1 & 5 & 5 & 4 & 4 & 4 & 3 & 3 & 39.49 \\
& & & & & & & & & & & & & & &
\end{tabular}

\section{MATERIAL RUANDES}

\begin{tabular}{llllllllllllllll}
\hline Clones & 1 & 2 & 3 & 4 & 5 & 6 & 7 & 8 & 9 & 10 & 11 & 12 & 13 & 14 & 15 \\
\hline RURB 12.2 & 1.85 & 1.70 & 7.0 & 5 & 9 & 2 & 1 & 1 & 4 & 2 & 1 & 2 & 3 & 3 & 27.44 \\
RURB 14.6 & 3.05 & 2.75 & 17 & 9 & 1 & 1 & 1 & 2 & 5 & 3 & 2 & 3 & 4 & 4 & 30.15 \\
RURB 14.15 & 3.15 & 3.15 & 13 & 13 & 6 & 3 & 1 & 3 & 5 & 4 & 4 & 2 & 5 & 5 & 29.59 \\
RURB 8.20 & 3.85 & 3.75 & 13 & 10 & 7 & 1 & 1 & 1 & 4 & 2 & 1 & 3 & 3 & 4 & 30.40 \\
RURB 10.12 & 1.18 & 1.35 & 4.0 & 3.7 & 6 & 1 & 1 & 2 & 5 & 3 & 3 & 2 & 4 & 4 & 32.94 \\
RURB 14.14 & 1.40 & 1.32 & 7.5 & 5.5 & 7 & 2 & 1 & 3 & 5 & 3 & 4 & 3 & 5 & 5 & 26.23 \\
RURB 9.14 & 1.13 & 1.05 & 6.3 & 4 & 8 & 2 & 1 & 3 & 5 & 4 & 2 & 2 & 4 & 3 & 31.70 \\
\hline
\end{tabular}

\section{MATERIAL PERUANO}

\begin{tabular}{llllllllllllllll} 
Clones & 1 & 2 & 3 & 4 & 5 & 6 & 7 & 8 & 9 & 10 & 11 & 12 & 13 & 14 & 15 \\
\hline ST.21 & 1.50 & 1.45 & 5.7 & 4.0 & 7 & 1 & 1 & 3 & 5 & 2 & 3 & 2 & 3 & 3 & 32.80 \\
SR88 054.14 & 1.00 & 1.00 & 3 & 3 & 2 & 4 & 1 & 4 & 6 & 3 & 4 & 3 & 4 & 4 & 31.33 \\
YM8-108.12 & 1.13 & 1.13 & 5 & 5 & 7 & 1 & 1 & 3 & 5 & 3 & 5 & 3 & 4 & 4 & 25.05 \\
LM88 072.20 & 1.65 & 1.65 & 4 & 4 & 8 & 1 & 1 & 4 & 5 & 3 & 3 & 3 & 4 & 4 & 25.64 \\
YM88 108.20 & 0.94 & 0.85 & 3.5 & 2 & 3 & 5 & 1 & 4 & 6 & 2 & 5 & 2 & 3 & 3 & 32.23 \\
YM88 i08.3 & 1.44 & 1.44 & 2.5 & 2.5 & 7 & 2 & 1 & 3 & 6 & 3 & 5 & 2 & 3 & 4 & 23.55 \\
ST.21 & 0.95 & 0.70 & 12 & 7 & 2 & 3 & 1 & 4 & 5 & 2 & 4 & 3 & 4 & 4 & 22.15 \\
ST87 040.1 & 1.30 & 1.30 & 5 & 5 & 2 & 3 & 1 & 3 & 5 & 3 & 4 & 3 & 4 & 4 & 24.25 \\
\hline
\end{tabular}

(1) 1. Peso total en $\mathrm{Kg}$.

2. Peso comercial en $\mathrm{Kg}$.

3. $N^{\circ}$ de raíces total

4. $N^{\circ}$ de raíces comerciales

5. Color de piel

6. Color de pulpa

7. Craking 
La naturaleza de la variabilidad genética presente en una población permite al fitomejorador determinar la metodología de selección en un programa de mejoramiento. El avance genético es lento en aquellas características que presentan poca variabilidad por medio de hibridaciones con material divergente. El rango refleja la magnitud de la variabilidad.

Los resultados del Cuadro 1 indican que el color de piel posee un rango de 1-9, muestra una media de $5.20+-2.30$ y una variabilidad de $43.1 \%$. El color de pulpa (carne) presenta un rango de 1-9, una media de $4.70+-2.50$ y una variabilidad de $53.3 \%$ El craking indica un rango de 0-1 una media de $1.00+-030$ y una variabilidad de $31.2 \%$. La pubescencia arroja un rango de $0-7$, una media de $2.50+-1.90$ y una variabilidad de $75.1 \%$.

El perfil de hoja muestra un rango de 3-7, promedio $4.40+-1.30$ y una variabilidad de $28.8 \%$. El tipo de lóbulo registra un rango de $1-9$, un promedio de 2.50 +-2.20 y una variabilidad $87.8 \%$.

El número de lóbulos presenta un rango de 15 , un promedio de $2.30+-1.80$ y una variabilidad de $79.0 \%$.

La forma de lóbulo presenta un rango de 1-9, un promedio de $2.40+-2.10$ y una variabilidad de $85.5 \%$. La pigmentación de venas tiene un rango de 1-7, media de $3.30+-1.50$ y una -variabilidad de $43.9 \%$. En la pigmentación de tallos se encontró un rango de 16, promedio de $3.20+1.70$ y una variabilidad de $53.4 \%$.

El peso total de raíces reservantes muestra un rango de 105.0 a $3550 \mathrm{~g}$. un promedio de 1062.8 +500.2 y una variabilidad de $47.1 \%$.

Los resultados obtenidos en las características cualitativas son similares a lo encontrado por Vargas y Luciani (1989).

Tanto las características cuantitativas y cualitativas han mostrado un alto grado de variabilidad. Esto permite hacer selecciones sin mayor dificultad y de manera eficiente.

\section{SELECCION DE CLONES EN LA POBLACIÓN RENDIMIENTO}

Es un carácter cuantitativo que se considera en la selección inicial de camote la cual esta gobernado por muchos genes.

Se han seleccionado 62 clones (14.31\%) (Cuadro 2) en base a su rendimiento, materia seca y aspectos cualitativos. 08 Clones son de orígen chino, 39 de orígen norteamericano, 11 de orígen japonés, 07 de orígen ruandés y 08 de orígen peruano.

Destacan por su rendimiento y buen aspecto el clon CHGU 3.12 con $3.40 \mathrm{Kg}$, buena cantidad de materia seca y calidad de piel y pulpa (Cuadro 2)

Los clones de orígen ruandés mostraron los mejores rendimientos con un promedio de $2.15 \mathrm{Kg}$. lo cual nos demuestra el éxito que viene obteniendo el programa de mejoramiento en aquel país. En segunda instancia destacan los clones norteamericanos que obtuvieron un rendimiento promedio de $1.53 \mathrm{Kg}$.

\section{CONTENIDO DE MATERIA SECA}

Es uno de los atributos mas deseables en las etapas iniciales de selección (Yoshida, 1995). Es de esperar que la transformación de azúcares de la parte aérea a la parte radicular sea alta a los $15^{\circ} \mathrm{C}$ pero que su transformación a almidón se maximice recién a los $30^{\circ} \mathrm{C}$, aunque la acumulación de esta no pueda sostenerse indefinidamente a esta temperatura debido al incremento de la lignificación y a la reducción de la activadad del cambium. A temperaturas elevadas también aumenta el aparato foliar, lo que determina una mayor cantidad de azúcares translocables (Del Carpio, 1988). Por otro lado está demostrado que el contenido de materia seca en las raíces generalmente disminuye a altos valores de $\mathrm{pH}$ (Bouwkamp, 1987).

El cuadro 2 presenta el contenido de materia seca de los clones seleccionados. Las diferencia s entre orígenes son evidentes.

Los clones norteamericanos y chinos poseen bajo contenido de materia seca entre 19.77 y $35.76 \%$.

Los clones japoneses tienen los contenidos más altos entre 23.39 a $41.64 \%$, lo cual demuestra el éxito del programa de mejoramiento japonés en este campo (Kukimura, et al 1990). Este material resulta promisorio para el desarrollo de líneas con alto contenido de almidón, y por ello, aparentes para usos industriales (Bouwkamp, 1987). Su incorporación más o menos rápida a programas de mejoramiento locales se justifica, además porque la herencia de este carácter está controlada principalmente por efectos aditivos y, parcialmente por efectos dominantes que inducen menores contenidos de almidón (Tarumoto et al, 1989). También es probable que estos clones tengan un mayor contenido de MS en la parte aérea.

Los clones peruanos presentan niveles de medios a altos entre 22.15 y $32.80 \%$ por lo que también puede ser interesante seleccionar por este carácter. 


\section{CARACTERISTICAS CUALITATIVAS}

En el Cuadro 2 se observa los caracteres cualitativos evaluados en el presente experimento. Se puede apreciar que los materiales de orígen ruandés tienen buen rendimiento sin embargo las raíces reservantes no son precisamente las mas deseadas lo cual desmerece la calidad.

Los materiales de orígen norteamericano y chino presentan aparentemente buenas características de piel y pulpa con colores amarillos y de carne anaranjado.

Las demás características cualitativas son variables en los diferentes clones y orígenes.

\section{CONCLUSIONES}

1. La variabilidad morfológica de la población fue amplia: peso total en gramos (47.1\%), peso comercial en

\section{BIBLIOGRAFIA}

1. AREVALO, S. N. 1992. Evaluación por adaptación de Germoplasma de camote (Ipomoea ba tatas (L).Lam) provenientes de cinco paí ses en cuatro localidades del Perú. Tesis Magister Scientiae. UNA La Molina.

2. BOUWKAMP, J.C y MACARDLE, R.N. 1987. Seedling screening techniques select high yielding genotypes of sweet potato. Horts cience 22 (1) : 111-113.

3. COLLINS et al. 1987. Genotype x environment interaction in sweet potato yield and quality factors. J.Amer.Soc. Hortsciencie 112 (3) : 579-583.

4. DEL CARPIO, R. 1988. La colección del camote gramos $(50.5 \%)$, color de piel $(43.1 \%)$, color de pulpa $(53.3 \%)$, craking $(31.2 \%)$, puescencia $(75.1 \%)$, perfil de hoja (28.8\%), tipo de lóbulo (87.8\%), número de lóbulos $(79.0 \%)$, forma de lóbulo $(85.5 \%)$, pigmentación de venas $(43.9 \%)$ y pigmentación de tallos $(53.4 \%)$.

2. Se ha seleccionado 62 clones (14.31\%) en base a su rendimiento, materia seca y aspectos cualitativos. 08 clones son de orígen chino, 39 de orígen norteamericano, 11 de orígen japonés, 07 de orígen ruandés y 08 de orígen peruano.

3. Los clones de orígen ruandés mostraron los mejores rendimientos con un promedio de $2,150 \mathrm{~g}$., en segunda instancia destacan los clones norteamericanos que obtuvieron un rendimiento promedio de $1,530 \mathrm{~g}$.

4. El clon CHGU 3.12 destaca con rendimiento de 3,400 $\mathrm{g} /$ planta y buen aspecto, buena cantidad de materia seca y calidad de piel y pulpa.

5.Los clones japoneses tienen los contenidos más altos de materia seca entre 23.39 a $41.64 \%$. Los clones norteamericanos y chinos poseen bajo contenido de MS entre 19.77 y $35.76 \%$.
5. KUKIMURA, H., KOMAKI, K., and YOSHINAGA, M. 1990. Current progress in sweet potato breding in Japan. JARQ 24 : 169-174.

6. TARUMOTO, I. 1989. Sweet potato breeding in Japan: Its Past, Present y Future. p 137-149. CIP. Improvement of sweet potato (Ipomoea batatas) in Asia.

7. VARGAS, G.S., LUCIANI, J.F. 1989. Rev. Fac. Agron. (Maracay). Alcance 38.

8. YOSHIDA, T. 1985. Correlation between succesive yield test for agronomic characters in sweet potato. Japan J. Breed. 35 : 204-208. 